Western University Scholarship@Western

Management and Organizational Studies

Management and Organizational Studies

Publications

Department

2014

\title{
The Motivating Role of Dissociative Outgroups in Encouraging Positive Consumer Behaviors
}

Katherine White

University of British Columbia

Bonnie Simpson

Western University, bonnie.simpson@uwo.ca

Jennifer Argo

University of Alberta

Follow this and additional works at: https://ir.lib.uwo.ca/mospub

Part of the Business Administration, Management, and Operations Commons, and the Work, Economy and Organizations Commons

Citation of this paper:

White, Katherine; Simpson, Bonnie; and Argo, Jennifer, "The Motivating Role of Dissociative Outgroups in Encouraging Positive Consumer Behaviors" (2014). Management and Organizational Studies Publications. 8.

https://ir.lib.uwo.ca/mospub/8 


\title{
KATHERINE WHITE, BONNIE SIMPSON, and JENNIFER J. ARGO*
}

\begin{abstract}
Previous research has found that people tend to avoid products or behaviors that are linked to dissociative reference groups. The present research demonstrates conditions under which consumers exhibit similar behaviors to dissociative out-group members in the domain of positive consumption behaviors. In particular, when a consumer learns that a dissociative out-group performs comparatively well on a positive behavior, the consumer is more likely to respond with positive intentions and actions when the setting is public (vs. private). The authors suggest that this occurs because learning of the successful performance of a dissociative out-group under public conditions threatens the consumer's group image and activates the desire to present the group image in a positive light. The authors show that although group affirmation mitigates these effects, self-affirmation does not. They also examine the moderating role of the positivity of the behavior and the mediating role of group image motives. Taken together, the results highlight conditions under which communicating information about the behaviors of dissociative out-groups can be used to spur consumers to engage in positive actions.
\end{abstract}

Keywords: reference groups, dissociative out-groups, sustainability, normative influence, public versus private

\section{The Motivating Role of Dissociative Out-Groups in Encouraging Positive Consumer Behaviors}

Research has consistently demonstrated that people will assert their distinctiveness from out-group members and avoid the attitudes and behaviors endorsed by members of such groups (Berger and Heath 2007, 2008; Brewer 1991; Tajfel and Turner 1986; White and Dahl 2006, 2007). The purpose of the present research is to examine a novel, counterintuitive effect wherein marketing communications that present consumers with information about the actions

*Katherine White is Associate Professor of Marketing, with a Professorship in Consumer Insights, Prosocial Consumption, and Sustainability, Sauder School of Business, University of British Columbia (e-mail: katherine. white@sauder.ubc.ca). Bonnie Simpson is Assistant Professor in Marketing, DAN Management and Organizational Studies, University of Western Ontario (e-mail: bonnie.simpson@uwo.ca). Jennifer J. Argo is Cormie Professor of Marketing, School of Business, University of Alberta (e-mail: jennifer.argo@business.ualberta.ca).The authors are grateful for funding from the Social Sciences and Humanities Research Council (SSHRC) and thank John Peloza for helpful comments on a previous version of this article. Jonah Berger served as associate editor for this article. of dissociative reference groups can be used to spur positive consumer behaviors that are consistent with the actions of the dissociative out-group. In particular, we propose that when a consumer encounters information highlighting that a dissociative out-group is performing at a comparatively high level on a positively viewed public behavior, the consumer will be more likely to engage in that same behavior. We suggest that this arises because learning about the relatively successful performance of a negatively viewed dissociative out-group in a positively viewed domain threatens one's group image and, under conditions in which the consumer is aware of his or her publicly displayed aspects (e.g., public contexts), heightens the desire to present one's own group in a positive light. In the sections that follow, we present our theoretical framework.

\section{THE INFLUENCE OF DISSOCIATIVE OUT-GROUPS ON CONSUMER BEHAVIOR}

Dissociative out-groups are social groups with which a person wants to avoid being associated (e.g., Englis and 
Solomon 1995; White and Dahl 2006, 2007). Extant research has suggested that dissociative referents consistently lead to an avoidance response on the part of consumers. That is, consumers tend to avoid, abandon, or negatively evaluate a product, brand, or behavior that is somehow linked with a dissociative reference group (Berger and Heath 2008; Berger and Rand 2008; Dunn, White, and Dahl 2012; Ferraro, Bettman, and Chartrand 2009; White and Dahl 2006, 2007). This is particularly the case when the domain is identity relevant (Berger 2008), when individual public self-image concerns are activated (White and Dahl 2006), or when the in-group identity is either primed or chronically important to the consumer (White and Dahl 2007). In one example of dissociative influence, White and Dahl (2006) find that men evaluate a product named the "ladies' cut steak" more negatively relative to the "chef's cut steak" because being labeled as female is a dissociative reference point for them. As a second example, in the domain of encouraging positive health behaviors, Berger and Rand (2008) demonstrate that highlighting a dissociative reference group engaging in a negative health behavior (e.g., drinking alcohol, unhealthy eating) can lead consumers to exhibit decreased intentions to engage in the behavior. Taken together, prior research has painted a consistent picture regarding dissociative reference group influence: people tend to exhibit an avoidance response to attitudes and behaviors endorsed by members of dissociative out-groups. The current research sets out to show a novel and counterintuitive effect by demonstrating that under certain conditions, consumers will exhibit an approach response toward the actions of dissociative referents, being more inclined to engage in the focal behavior. Specifically, the current work proposes that providing information regarding the comparatively positive actions of a dissociative out-group can impel consumers to be more likely to engage in the activity.

Although research has not explicitly tested our predictions, support for this possibility is found in work showing that consumers exhibit approach responses to learning of the actions of a counterstereotypical product user. In particular, Shalev and Morwitz (2012) find that when a counterstereotypical product user (i.e., a low-status user) evaluates a technological product positively, this can lead to positive product evaluations on the part of an observer. This is especially likely to be the case for observers who view the trait of innovativeness as being important to their individual self and for those who are uncertain about their standing on the focal trait. Shalev and Morwitz (2012) identify a process at the level of the individual self that underlies these effects, whereby comparing oneself with a counterstereotypical user diminishes one's self-evaluation and, in turn, leads the person to restore his or her individual self-image. The authors propose that learning about a counterstereotypical user (i.e., someone who is typically not expected to use the product) might lead one to estimate that the average level on the focal trait (e.g., innovativeness) is higher than expected. As a result, the consumer will infer that his or her standing on the trait is lower than previously believed, which, in turn, threatens the consumer's self-concept. Importantly, in our context, we propose that consumers will engage in a behavior that is consistent with a dissociative reference group because of a group-level motive (i.e., a desire to present the group image in a positive light).

\section{CAN DISSOCIATIVE REFERENCE GROUPS LEAD TO APPROACH RESPONSES?}

As a preliminary test of the notion that dissociative reference groups might, under certain conditions, impel consumers to be more likely to engage in the focal behavior, we conducted a pilot study. In this study, as with those that follow, we examine our predictions in the domain of sustainable consumer behaviors because pretesting indicated that sustainable actions such as composting, recycling, and conserving water were all viewed as highly positive. Furthermore, encouraging sustainable consumer behaviors addresses one of society's most critical challenges (Organisation for Economic Co-operation and Development 2008; Peattie 2010) because we are currently faced with numerous environmental concerns including habitat destruction, water insufficiencies, and the accumulation of excess waste. For example, the average North American uses 400 liters of water per day (Wateraid 2013) and discards materials in landfills after using them only once (approximately $76 \%$ of the time), even though many of these materials could easily be reused, recycled, or composted (Environmental Protection Agency 2011). The focal sustainable consumer behavior of interest in our pilot study is composting, which is the purposeful separation and biodegradation of organic matter, such as food waste, rather than throwing it in the mixed garbage (White and Simpson 2013).

The study was conducted in conjunction with a coffee shop frequented by business school students and located in the school of business at a major university. In the study, participants learned about the composting behavior of a dissociative out-group (i.e., computing science students), a membership group (i.e., business students), or no one (i.e., a control group). A pretest confirmed the effectiveness of this manipulation (see Appendix A). In the main study, a research assistant posing as a coffee shop employee approached students $(n=140)$ seated in the public area surrounding the coffee shop and offered them a free sample of a coffee product. In all conditions, the research assistant said to participants, "By the way, the cup is compostable." In the dissociative out-group (membership group) condition, the research assistant also said, "We are trying to encourage students to compost because of a new initiative on campus. Recently, a survey was conducted and it found that Computing Science (Business) students are the most effective in composting efforts when compared across the student groups." In the control condition, participants were not given any further information. Unbeknownst to participants, an unobtrusive observer recorded whether they later placed their coffee cup in the composting bin that was located nearby. Chi-square analysis revealed that whereas only $7.7 \%$ of those in the control condition and $10.2 \%$ of those in the membership group condition composted their cups, $25 \%$ of those in the dissociative out-group condition composted their coffee cups $\left(\chi^{2}=6.60, p<.05\right)$.

This pilot study offers preliminary evidence that providing information about the behavior of a dissociative out-group can increase the propensity for consumers to engage in that same behavior. However, the pilot study does not address when such effects might predictably emerge. We propose that these approach intentions and behaviors in reaction to the comparatively positive performance of a dissociative 
reference group will be more likely to emerge when consumers' responses are public rather than private. Indeed, a posttest confirmed that the location of the pilot study, which was conducted in a busy area of the building by the coffee shop, was considered highly public (posttest, Appendix A). We next turn to our predictions regarding the moderating role of the public versus private nature of the setting.

\section{THE PUBLIC VERSUS PRIVATE NATURE OF THE SETTING}

Public settings tend to heighten public self-awareness or sensitivity to the fact that public aspects of the self can be observed and evaluated by others (Turner and Crisp 2007). As such, public contexts tend to increase behaviors that enable one to present a positive self-view to other people (Froming, Walker, and Lopyan 1990; Ratner and Kahn 2002; White and Dahl 2006; White and Peloza 2009). We propose that when a public (vs. private) setting is combined with information that casts one's membership group in a negative light (i.e., one learns that a dissociative out-group has performed comparatively well on a positively viewed behavior), the consumer's group image will become threatened. This threat emerges because the public setting increases a sense of awareness of being evaluated by others. When this awareness is combined with information that the dissociative out-group has performed comparatively well on the positive behavior, this increases the sense that the membership group has somehow fallen short. This group image threat will, in turn, lead to an increased desire on the part of the consumer to present his or her own group image in a positive light. To do so, the consumer is expected to demonstrate an increased tendency to endorse and engage in the positively viewed behavior exhibited by the dissociative out-group. In summary, we anticipate that consumers will show increased intentions and behaviors after learning about the comparatively positive performance of a dissociative out-group when the context is public (vs. private). Given that we propose that our effects are driven by a threat that arises from a comparison with a dissociative group, we include a point of comparison from which no threat should arise and thus examine the impact of learning about the comparative successful performance of one's membership group. Because learning that one's membership group performs comparatively well on a positively viewed behavior does not threaten the group image, this information will not lead to differential intentions and behaviors as a function of whether the context is public or private. Thus, we predict the following:

$\mathrm{H}_{1 \mathrm{a}}$ : When a consumer learns that a dissociative out-group is performing comparatively well on a positive behavior, he or she will report greater intentions and behaviors to engage in the same behavior when the context is public (vs. private).

$\mathrm{H}_{1 \mathrm{~b}}$ : When a consumer learns that his or her membership group is performing comparatively well on a positive behavior, no differences in intentions and behaviors to engage in the same behavior will emerge as a function of whether the context is public versus private.

\section{THE CURRENT RESEARCH}

In the studies that follow, we examine the conditions under which comparative information regarding the actions of a dissociative out-group can be used to influence positively viewed consumer behaviors such as composting (Studies 1 and 2), recycling (Study 3), and conserving water (Study 3 follow-up). The current research makes several notable contributions to the literature. First and foremost, to our knowledge, this research is the first to test the notion that communicating information regarding the successful performance of a dissociative reference group can lead to congruent responses whereby consumers are inclined to engage in the same behavior demonstrated by the dissociative out-group. Second, we identify boundary conditions for these effects by showing that people are more likely to engage in positive actions in response to dissociative reference groups under conditions in which the setting is public (vs. private) (Studies 1 and 3 ) and that this occurs only for positive (vs. negative) behaviors (Study 3).

Third, we provide evidence that the mechanism underlying the effects arises at the group level of the self. In particular, we demonstrate that learning that a dissociative out-group has performed comparatively well on a positively viewed behavior in public contexts will (1) threaten a consumer's group image and (2) activate the desire to present one's group in a positive light. We achieve the former by showing that the effects are attenuated by a group-affirmation task (Study 2). We achieve the latter by demonstrating that the process underlying the effects is such that comparative concerns lead to the activation of group image motives, which then influence positive intentions to engage in the behavior (Study 3). This is an important contribution to the literature because although prior work has suggested that associative attitudes toward a counterstereotypical person can be driven by an individual-level response (Shalev and Morwitz 2012), we demonstrate conditions under which information regarding the behaviors of a dissociative out-group can activate a group-level response that drives associative individual responses. In addition, we contribute to the reference group literature stream by revealing situations in which image management concerns can lead consumers to act in congruence with a dissociative reference group, whereas previous research has shown only that image management concerns can lead to avoidant responses in relation to the behaviors of dissociative out-groups (Berger and Heath 2007; White and Dahl 2006, 2007).

\section{STUDY 1}

Study 1 tests our prediction that when information is communicated about the positive sustainable actions of a dissociative out-group, consumers will be more inclined to engage in the same behavior when the setting is public (vs. private). We describe our method and results in the following subsections.

\section{Method}

Participants. Ninety-three undergraduate business students participated in a 2 (setting: public vs. private) $\times 2$ (reference group: dissociative out-group vs. membership group) between-subjects experimental design in exchange for partial course credit. Participants completed the study in small groups of four to ten people.

Procedure. Upon arrival, participants were informed that the study was interested in people's attitudes and intentions toward a new composting program that was being intro- 
duced on campus. The setting was manipulated at the beginning of the session. In the public condition, the experimenter told participants that their composting intentions and attitudes would be discussed with others in the study at the end of the session. In the private condition, participants were told that their responses would be kept anonymous and confidential (see White and Peloza 2009). Participants then viewed a press release regarding a new composting program that ostensibly served the purpose of allowing them to familiarize themselves with the topic of composting on campus. The press release described the new composting initiative and then manipulated reference group by stating that either computing science students (dissociative outgroup) or business students (membership group) were "the most effective in composting efforts when comparing across the student groups" (Appendix B). After reading the press release, participants completed the dependent measure, behavioral intentions toward composting, through a series of seven-point scales (Appendix A, composting intentions index, $\alpha=.879$ ).

Participants then completed demographic measures and a suspicion probe and were debriefed. In this study, gender neither predicted nor interacted with the other independent variables to predict significant variance in the dependent variable. This was true across all the studies and is not discussed further. In addition, participants did not report suspicion about the study procedures or guess the nature of the hypotheses in this study. This is also true across the remaining studies and is not discussed further. As a check to ensure that participants understood the reference group manipulation, at the end of the study participants were asked to recall the specific reference group mentioned in the press release. In addition, as a check for the setting manipulation, participants reported how public or private they expected their responses to be on seven-point scales (Appendix A, publicprivate index, $\alpha=.84$ ).

\section{Results and Discussion}

Manipulation checks. When selecting for those in the dissociative out-group condition, $88 \%$ of participants correctly recalled the reference group; when selecting for those in the membership group condition, $89 \%$ of participants correctly recalled the reference group. These percentages did not significantly differ across levels of the setting manipulation for those in the dissociative out-group condition $\left(\chi^{2}=1.81\right.$, n.s.) or membership group condition $\left(\chi^{2}=3.26\right.$, n.s.). In addition, a setting $\times$ reference group analysis of variance (ANOVA) on the public-private index revealed a main effect only for setting $(\mathrm{F}(1,89)=32.24, p<.001)$, indicating that those in the public condition viewed their responses as being relatively more public $(\mathrm{M}=4.02)$ than did those in the private condition $(\mathrm{M}=2.61)$. The main effect for reference group $(F(1,89)=.001$, n.s. $)$ and the interaction of setting and reference group $(\mathrm{F}(1,89)=.28$, n.s. $)$ did not reach significance. Thus, we deem our manipulations successful.

Composting intentions. A setting $\times$ reference group ANOVA on composting intentions revealed a significant interaction $(\mathrm{F}(1,89)=4.27, p<.05$; Figure 1$)$. The main effects for setting $(\mathrm{F}(1,89)=.63$, n.s.) and reference group $(\mathrm{F}(1,89)=.20$, n.s. $)$ did not reach significance. We then conducted planned contrasts as outlined in Howell (1997; see also McFarland and Miller 1994; White and Peloza
Figure 1

COMPOSTING INTENTIONS AS A FUNCTION OF SETTING AND REFERENCE GROUP (STUDY 1)

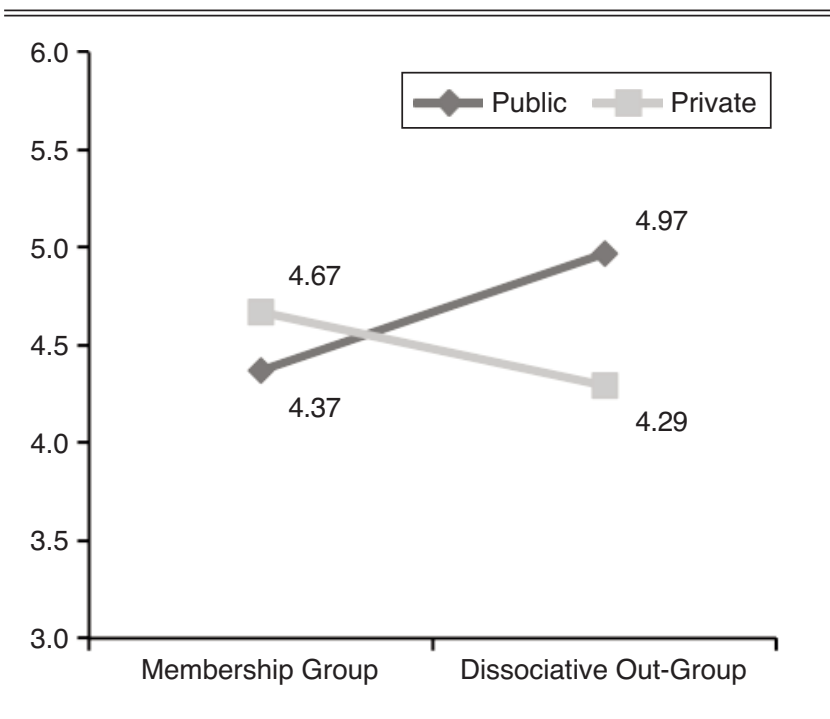

Notes: Mean scores are reported.

2009). As we predicted in $\mathrm{H}_{1 \mathrm{a}}$, in the dissociative out-group condition, participants were more inclined to compost when the setting was public $(\mathrm{M}=4.97)$ than when it was private $(\mathrm{M}=4.29 ; \mathrm{t}(89)=2.00, p<.05)$. Consistent with $\mathrm{H}_{1 \mathrm{~b}}$, in the membership group condition, no significant differences in composting intentions emerged as a function of setting $\left(\mathrm{M}_{\text {public }}=4.37, \mathrm{M}_{\text {private }}=4.67 ; \mathrm{t}(89)=1.14\right.$, n.s. $)$. Viewing the data another way, when selecting for the public setting, participants in the dissociative out-group condition $(\mathrm{M}=$ 4.97 ) reported marginally more positive intentions than those in the membership group condition $(\mathrm{M}=4.37$; $\mathrm{t}(89)=$ $1.79, p<.08)$. When selecting for the private condition, no differences emerged across the membership group $(\mathrm{M}=$ $4.67)$ versus dissociative out-group conditions ( $M=4.29$; $\mathrm{t}(89)=1.14, p>.25)$.

Discussion. The results of Study 1 support our conceptualization. In particular, when information conveying the positive sustainable actions of a dissociative out-group is presented, consumers report more favorable composting intentions when the setting is public than when it is private. In contrast, when information highlights the positive sustainable actions of a membership group, no differences in composting intentions emerge as a function of setting.

The results of Study 1 provide evidence for the notion that, under certain conditions, consumers exhibit approach responses to the behaviors of dissociative out-groups. In the studies that follow, we focus more specifically on the process underlying the observed effects. Recall that our conceptualization proposes that learning that a dissociative out-group has performed comparatively well on a positively viewed behavior in public situations will (1) threaten a consumer's group image and (2) activate the desire to present the group in a positive light. To test the first step in our proposed process, we examine the moderating role of group affirmation (Study 2). To test the second step of our conceptualization, we explore the mediating role of group image motives (Study 3). 


\section{STUDY 2}

The main objective of Study 2 is to demonstrate that when the setting is public, learning of the comparatively successful performance of a dissociative out-group on a positively viewed behavior threatens one's group image. To do so, we draw on self-affirmation theory, which proposes that people have a desire to protect and maintain selfintegrity or self-worth (Steele 1988). According to the theory, when self-worth is threatened, people respond in ways that enable them to restore self-worth (Steele 1988; Steele and Liu 1983; White and Argo 2009). Furthermore, the theory proposes that when a person is threatened and then given the opportunity to restore feelings of self-worth through an alternative means (e.g., through affirming important individual self-values), self-protective reactions to threat are often mitigated (Steele 1988; Steele and Liu 1983). Importantly, affirmation can occur not only at the individual level but also at the group level of the self (e.g., Derks, Van Laar, and Ellemers 2009; Hoshino-Browne et al. 2001; Sherman et al. 2007; White, Argo, and Sengupta 2012).

Recall that our conceptual framework proposes that receiving information about the comparative positive performance of a dissociative out-group threatens the group image when the setting is public. Building on this logic, we expect that a group-affirmation task should satisfy the desire to present the group image in a positive light (e.g., HoshinoBrowne et al. 2001; White, Argo, and Sengupta 2012). Thus, a group-affirmation task should diminish the tendency for consumers to exhibit similar intentions and behaviors to those of a dissociative out-group. Importantly, our framework suggests that this response to the dissociative group information should not be attenuated when the task affirms the individual self or when no affirmation task is given. However, learning that one's membership group has performed comparatively well is not particularly threatening to the group or individual level of the self, and therefore, we do not anticipate any differences across affirmation conditions. In summary, we predict that when the setting is public,

$\mathrm{H}_{2 \mathrm{a}}$ : The tendency to exhibit increased intentions in response to learning that a dissociative out-group is performing comparatively well on a positive behavior is lower in the group-affirmation condition compared with the selfaffirmation and no-affirmation conditions.

$\mathrm{H}_{2 \mathrm{~b}}$ : When a consumer learns that his or her membership group is performing comparatively well on a positive behavior, no differences in intentions and behaviors to engage in the same behavior emerge as a function of the affirmation type.

\section{Method}

Participants and design. One hundred eighteen undergraduate business students participated in a 2 (reference group: dissociative out-group vs. membership group) $\times 3$ (affirmation type: self-affirmation vs. group affirmation vs . no affirmation) between-subjects design in return for partial course credit. The study was completed in small groups of four to ten participants, and the setting was held constant as public. Again, the focal dependent variable was composting intentions.
Procedure. Upon arrival, participants were informed that there were several tasks for them to complete during the session. All participants were exposed to the public setting manipulation condition as described in Study 1. Participants were then given the affirmation type manipulation modeled after previous research (e.g., Hoshino-Browne et al. 2001; Steele 1988; White and Argo 2009; White, Argo, and Sengupta 2012). Participants were told that the task was a measure of personality and were asked to rank-order 11 traits and values. In the self-affirmation condition, they were asked to rank the values in terms of "their importance to you," to write about why their first-ranked value was important to them, and to describe a time in their lives (real or hypothetical) when that value was meaningful to them. In the groupaffirmation condition, participants were asked to rank-order the values in terms of "their importance to yourself and fellow business students," to write about why the first-ranked value may have been important to them and their fellow business students, and to describe a time (real or hypothetical) when this value was important to them and their fellow business students. In the no-affirmation condition, participants were asked to rank-order the values in terms of "their importance to the typical person," to write about why the number-one value might be important to the typical person, and to describe a time (real or hypothetical) when this value might have been important to the typical person. Participants then viewed the same manipulation of reference group used in Study 1. Finally, participants completed the same composting intentions measure described in Study $1(\alpha=$ $.854)$.

\section{Results and Discussion}

Composting intentions. A 2 (reference group: dissociative out-group vs. membership group) $\times 3$ (affirmation type: self-affirmation vs. group affirmation vs. no affirmation) ANOVA revealed a significant two-way interaction $(\mathrm{F}(2$, $112)=3.25, p=.05$; see Figure 2). The main effects for ref-

Figure 2

COMPOSTING INTENTIONS AS A FUNCTION OF REFERENCE GROUP AND AFFIRMATION TYPE (STUDY 2)

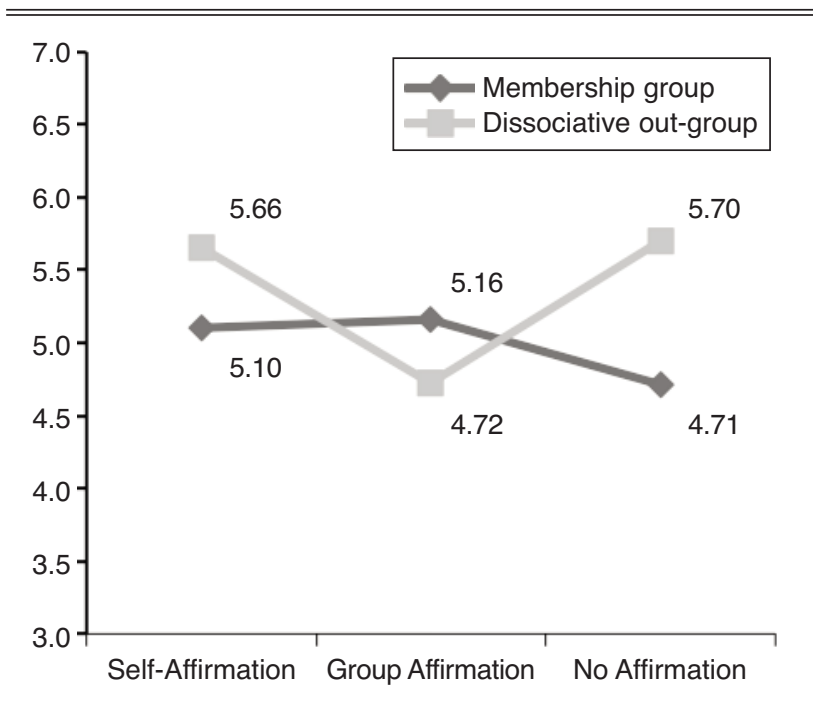

Notes: Mean scores are reported. The setting is held constant as public. 
erence group $(\mathrm{F}(2,112)=1.99, p<.17)$ and affirmation type $(F(2,112)=.84$, n.s. $)$ did not reach significance. As we predicted, when receiving information regarding the actions of a dissociative out-group, participants reported reduced composting intentions in the group affirmation condition $(\mathrm{M}=4.72)$ compared with the self-affirmation $(\mathrm{M}=5.66$; $\mathrm{t}(112)=2.29, p<.05)$ and the no-affirmation $(\mathrm{M}=5.70$; $\mathrm{t}(112)=2.48, p<.05)$ conditions. When the information about the positive actions of a membership group was communicated, composing intentions did not differ for the group-affirmation $(\mathrm{M}=5.16)$, the self-affirmation $(\mathrm{M}=$ $5.10)$, and the no-affirmation $(\mathrm{M}=4.71)$ conditions (all ts < 1.12 , n.s.).

Viewing the data another way, under conditions of no affirmation, those in the dissociative out-group condition exhibited more positive intentions $(M=5.70)$ than those in the membership group condition $(\mathrm{M}=4.71 ; \mathrm{t}(112)=2.50$, $p<.05)$. When selecting for the group affirmation condition, those in the dissociative out-group condition exhibited similar intentions $(M=4.72)$ to those in the membership group condition $(\mathrm{M}=5.16 ; \mathrm{t}(112)=1.07$, n.s. $)$. In addition, when selecting for the self-affirmation condition, those in the dissociative out-group condition exhibited similar intentions $(\mathrm{M}=5.66)$ as those in the membership group condition $(\mathrm{M}=5.10 ; \mathrm{t}(112)=1.31, p<.02)$. We note that although neither the group- nor self-affirmation conditions show a difference between the dissociative and membership conditions, given that affirmation tasks serve to reduce reactions to threatening circumstances (e.g., Steele 1988), the crucial comparison is across the conditions in which threat is present. Thus, the more telling analysis compares the results in which a dissociative out-group performs comparatively well on the task to observe under which circumstances consumer reactions to the threat are mitigated. In this case, it is only in the group-affirmation condition that evaluations are more negative than in the no-affirmation condition (i.e., there are no differences in intentions between the self-affirmation and no-affirmation groups when information is provided about the performance of a dissociative out-group).

Discussion. The results of Study 2 support the proposition that our effects are driven by a group-level (vs. individuallevel) response. In particular, under public conditions, when information regarding the comparatively positive performance of a dissociative out-group was presented, a groupaffirmation task significantly reduced composting intentions compared with a self-affirmation task or a no-affirmation task. When information about the positive performance of the membership group was presented, affirmation type did not differentially predict composting intentions. These results support the notion that whereas information regarding the positive sustainable actions of a membership group does not threaten the individual or group level of the self, information regarding the positive sustainable actions of a dissociative out-group is threatening to the self at the group level but not the individual level.

\section{STUDY 3}

The goal of Study 3 is to extend the results of the previous studies in several ways. First, as indicated previously, our theorizing posits that the effects should arise only when the information about the dissociative out-group casts one's own group image in a negative light. Following this line of reasoning, learning about the successful performance of a dissociative out-group should motivate a consumer's willingness to engage in the action when the behavior is positive but not negative. This is because whereas learning about a dissociative group's strong performance on a positive behavior has the potential to make the consumer's membership group look bad comparatively, learning about a dissociative group's high performance on a negative behavior does not have this same potential. Thus, we predict that the positivity of the behavior will moderate our findings such that the effects will emerge for a positive behavior (i.e., recycling), but not a negative one (i.e., littering). We chose these two behaviors because although both involve waste disposal, pretesting showed that recycling was evaluated more positively than littering $\left(n=48 ; M_{\text {recycling }}=6.71\right.$ vs. $\mathrm{M}_{\text {littering }}=1.34$; see Appendix A). In particular, we predict the following:

$\mathrm{H}_{3 \mathrm{a}}$ : Under conditions in which the behavior is viewed as being positive, when a consumer learns that a dissociative outgroup is performing comparatively well, he or she will report greater intentions to engage in the same behavior when the setting is public (vs. private).

$\mathrm{H}_{3 \mathrm{~b}}$ : Under conditions in which the behavior is viewed as being negative, when a consumer learns that a dissociative outgroup is performing comparatively well, he or she will not report differences in intentions to engage in the same behavior regardless of whether the setting is public or private.

The second purpose of Study 3 is to elucidate the process underlying our effects. Our conceptual framework suggests that under public conditions, a comparative process that casts the membership group in a negative light (e.g., a dissociative out-group group is outperforming the membership group on a positively viewed behavior) threatens the group image, leading to concerns about presenting a positive group image to others. This, in turn, leads the person to increase his or her inclination to engage in the focal behavior. Previous theorizing on social comparison processes has suggested that negatively comparing one's performance to that of others can lead to increases in performance along the threatened dimension (e.g., Festinger 1957). Following from the aforementioned predictions, we test whether our effects are driven by a comparative concerns $\rightarrow$ group image concerns pathway.

With Study 3, we also aim to test several alternative explanations for the observed results. First, it is possible that our effects are not driven by a comparative process but rather by a more explicit competitive motive to compete against and outperform the other group (Berger and Pope 2011). We thus measure both comparative concerns (i.e., concerns that the membership group is performing worse than the dissociative group) and explicit competition (i.e., the explicit desire to outperform the dissociative group; e.g., Tauer and Harackiewicz 1999). In addition, it may be that the effects are driven in part by individual self-image concerns rather than group image concerns. As such, we measure individual self-image concerns (i.e., concerns about the image being projected to others by the self; White and Dahl 2006) and group image concerns (i.e., concerns about the image being projected to others by the group). Finally, it is possible that accountability to the membership group might drive the effects. Thus, we also measure accountability (i.e., 
a tendency to feel responsible for the group's performance; Baumeister, Masicampo, and DeWall 2009). In summary, although we anticipate that the activation of comparative concerns will lead to increased group image concerns, which will in turn lead to a heightened tendency to engage in the positive behavior, we do not believe that individual image concerns, the explicit desire to compete with the group, or accountability will mediate the effects.

$\mathrm{H}_{4}$ : Our effects are mediated by a comparative concerns $\rightarrow$ group image concerns pathway.

An additional goal of Study 3 is to generalize our findings in several ways. It is possible that in the previous studies, the reference groups used to operationalize dissociative out-groups and membership groups (i.e., computer science students and business students, respectively) differed on additional characteristics beyond the purpose of our manipulation. Thus, to enhance the generalizability of our effects, we use a different operationalization of reference group (i.e., province of residence). Another consideration is whether communicating the performance of any out-group will lead to the observed effects or whether the effects emerge only in response to an out-group that is viewed as being dissociative. To explore this possibility, we include a neutral out-group along with a dissociative out-group and a membership group.

Finally, we wanted to employ a different manipulation of the degree to which the setting is public or private to better disentangle what is driving the observed effects. As we noted previously, we believe our results emerge because the public (vs. private) setting activates awareness of being evaluated by others (i.e., public self-awareness). However, it is possible that the manipulation of setting used in Studies 1 and 2 might have increased not only public self-awareness but also accountability (Lerner and Tetlock 1999). Thus, in Study 3 we use an alternative manipulation of public versus private setting that varies self-awareness while holding accountability constant: videotaping participants. Previous research has shown this procedure to increase awareness of publicly displayed aspects of the self (e.g., Froming, Walker, and Lopyan 1982; Hass 1984; White and Peloza 2009).

\section{Method}

Participants and design. Two hundred sixty-one university students (145 women, mean age $=21.54$ years) were recruited for a study of consumer waste disposal behaviors. The study design was a 2 (setting: public vs. private) $\times 3$ (reference group: dissociative out-group vs. membership group vs. neutral out-group) $\times 2$ (behavior type: positive vs negative) between-subjects design. The study was completed in small groups of four to ten people.

Pretests. Because we used participants' province of residence to manipulate the nature of the reference group, we conducted a pretest to confirm what provinces would be viewed as a dissociative out-group, a membership group, and a neutrally viewed out-group. Thirty-four participants who were permanent residents of the home province in which the study was conducted rated their own province (i.e., Alberta) and other provinces using the same scales as described in the Study 1 pretest (Appendix A; $\alpha$ s from .877 to .899 ). The results confirmed that the home province was viewed as being less dissociative than the scale midpoint $(\mathrm{M}=$ $2.34 ; \mathrm{t}(47)=8.61, p<.001)$. In addition, we identified one out-group province that was viewed as being more dissociative than the midpoint (i.e., Quebec; $M=4.75$; $\mathrm{t}(47)=3.72$, $p<.05)$ and one out-group province that was viewed as being neutral (i.e., Manitoba was not different than the scale midpoint; $\mathrm{M}=3.99, \mathrm{t}(48)=.05$, n.s.).

Procedure. Upon arrival, participants were informed that the study was interested in examining people's attitudes and intentions toward improving waste disposal programs being implemented across Canada. The public setting manipulation was achieved following a procedure outlined in White and Peloza (2009). In the public condition, participants were informed that the study session would be video recorded because the researcher might want to use the footage for presentations in the future, and a video camera was directed at the group and actively taped the sessions. In the private condition, the camera was present in the room but turned away from participants, and they were told that it would not be used to record their session. Participants then read a press release about improving waste disposal programs in Canada that ostensibly served the purpose of familiarizing them with the topic. The press release described the waste disposal initiative-encouraging recycling in the positive condition and preventing litter in the negative condition - and then manipulated reference group by stating that either the membership group residents, neutral out-group residents, or dissociative out-group residents are "the most effective in their recycling when comparing across the provinces" or "litter most often when comparing across the provinces."

Participants then completed items to assess behavioral intentions toward both recycling (recycling intentions scale: $\alpha=.865$ ) and littering (littering intentions scale: $\alpha=.779$; Appendix A). ${ }^{1}$ We aimed to demonstrate that our effects are related to comparative concerns, which in turn activate group image concerns but not explicit competition concerns, individual image motives, or accountability. Thus, participants completed items to assess comparative concerns $(\alpha=.791)$, explicit competition concerns $(\alpha=.934)$, group-level image concerns $(\alpha=.899)$, individual image concerns $(\alpha=.854)$, and accountability $(\alpha=.791)$ (Appen$\operatorname{dix}$ A). Finally, participants indicated their province of residence. Twenty-one participants indicated that the membership group province was not their place of residence, so we removed these cases from our analysis to ensure a proper manipulation of reference group.

\section{Results}

Recall that our conceptualization suggests that our observed effects should emerge for a positively (vs. negatively) viewed behavior. We first examined the effects for the positive behavior of recycling. A univariate ANOVA revealed that the interaction between reference group and setting significantly predicted recycling intentions $(\mathrm{F}(2$, $121)=4.60, p<.05$; see Figure 3$)$. The main effects for set-

${ }^{1}$ Note that although all participants completed both the recycling and the littering items, they completed the focal behavioral items first (i.e., people in the recycling [littering] condition completed the recycling [littering] items first), and our analyses examine the relevant behavioral intentions for the respective condition. 
Figure 3

COMPOSTING INTENTIONS AS A FUNCTION OF SETTING, REFERENCE GROUP, AND BEHAVIOR TYPE (STUDY 3)
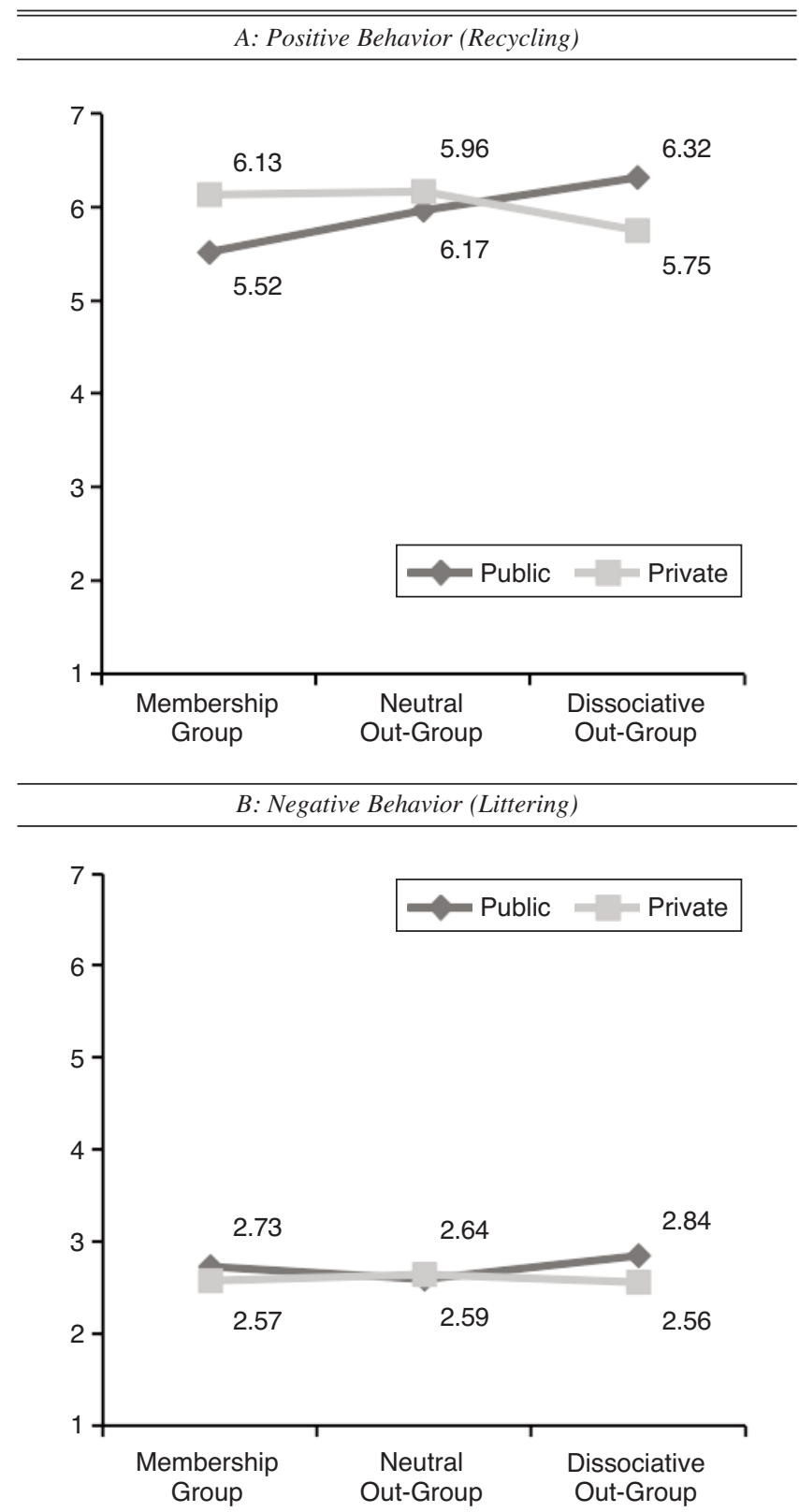

Notes: Mean scores are reported.

ting $(\mathrm{F}(2,121)=.26$, n.s. $)$ and reference group $(\mathrm{F}(2,121)=$ .86, n.s.) did not reach significance. When the reference group was a dissociative out-group, higher positive behavioral intentions emerged when the setting was public $(\mathrm{M}=$ $6.32)$ as opposed to private $(\mathrm{M}=5.75 ; \mathrm{t}(121)=2.08, p<$ $.05)$. When the reference group was a neutral out-group, no differences in positive behavioral intentions emerged regardless of whether the setting was public $(M=5.96)$ or private $(\mathrm{M}=6.17 ; \mathrm{t}(121)=.79$, n.s.). Finally, when the reference group was a membership group, participants reported significantly less positive behavioral intentions when setting was public $(\mathrm{M}=5.52)$ as opposed to private $(\mathrm{M}=6.13 ; \mathrm{t}(121)=2.12, p<.05)$. We note that we did not anticipate this latter finding, and we address this result in the "General Discussion" section.

Analyzing the results in another way, when the setting was public, those in the dissociative out-group condition reported more positive behavioral intentions $(\mathrm{M}=6.32)$ than those in the membership condition $(\mathrm{M}=5.52 ; \mathrm{t}(121)=$ $2.96, p<.05$ ), but not more positive behavioral intentions than those in the neutral condition $(\mathrm{M}=5.96 ; \mathrm{t}(121)=1.34$, $p>.18$ ). When the setting was private, no differences emerged between the reference group conditions (all ts < 1.32). Finally, when examining the negatively viewed behavior (littering), neither the main effects for public selfawareness $(\mathrm{F}(2,107)=.26$, n.s. $)$ and reference group $(\mathrm{F}(2$, $107)=.51$, n.s. $)$ nor the interaction $(\mathrm{F}(2,107)=.26$, n.s.; see Figure 3) reached significance.

Mediation analysis. Our framework proposes that when the behavior is positive, the interaction between reference group and setting will predict comparative concerns, which will lead to group image concerns and then predict recycling intentions. To examine the proposed mediating pathway of the interaction $\rightarrow$ comparative concerns $\rightarrow$ group image motives $\rightarrow$ recycling intentions, we first dummycoded the reference group condition to compare the membership group with the dissociative group. We then entered the interaction as a predictor of a serial mediation pathway wherein comparative concerns predict group-image motives, which in turn predict recycling intentions (while also entering the main effects into the analysis; PROCESS model 6; Hayes 2013). We obtained the $95 \%$ bias-corrected and accelerated (BCa) bootstrap confidence interval (CI) (-.0941, -.0082 ). We found that zero was not included in the lower and upper bounds of the confidence interval (Zhao, Lynch, and Chen 2010), indicating that the comparative concerns $\rightarrow$ group image motives pathway was a significant mediator in predicting recycling intentions. Our prediction is further supported by viewing the effect at the different levels of the moderator (setting). Whereas the mediational pathway was not significant when selecting for the private setting (CI: $[-.0137, .0236])$, it was significant when selecting for the public setting (CI: $[-.0970,-.0028]$ ).

An alternative way to view the data is to create a dummycoded variable such that the dissociative reference group is coded as -1 and the other two reference group conditions are coded as 1 . When running the same mediational pathway as before, using this coding, we again obtained the $95 \%$ BCa bootstrap CI of $(-.0925,-.0075)$, in support of the predicted mediation. To address the possibility of alternative mechanisms underlying our effects, we conducted additional mediation analyses, which we present in Table 1. None of the other potential mediators adequately account for the observed effects in the current study.

Discussion. Using alternative manipulations for both the nature of the setting and reference group, Study 3 demonstrates key boundary conditions of the observed effects. First, when consumers learn of the successful performance of a dissociative out-group on a positive (vs. negative) behavior, they are more inclined to engage in that behavior when the setting is public than private. Second, intentions did not differ for those in the neutral out-group condition as a function of the setting. Finally, although participants reported increased composting intentions in response to the dissociative out-group as opposed to the membership group, 
Table 1

MEDIATIONAL ANALYSIS FOR STUDY 3

\begin{tabular}{lcc}
\hline \hline Mediational Pathway & $95 \%$ BCa Bootstrap CI & Statistical Mediation \\
\hline Interaction $\rightarrow$ comparative concerns $\rightarrow$ group image motives $\rightarrow$ recycling intentions & $(-.0941,-.0082)$ & Yes \\
Interaction $\rightarrow$ comparative concerns $\rightarrow$ individual image motives $\rightarrow$ recycling intentions & $(-.0150, .0073)$ & No \\
Interaction $\rightarrow$ explicit competition concerns $\rightarrow$ group image motives $\rightarrow$ recycling intentions & $(-.0684, .0174)$ & No \\
Interaction $\rightarrow$ explicit competition concerns $\rightarrow$ recycling intentions & $(-.1625, .0849)$ & No \\
Interaction $\rightarrow$ individual self-image motives $\rightarrow$ recycling intentions & $(-.1263, .2130)$ & No \\
Interaction $\rightarrow$ accountability $\rightarrow$ recycling intentions & $(-.2007, .1285)$ & No \\
\hline
\end{tabular}

they did not report differential composting intentions in response to the neutral out-group compared with the membership group. Thus, it seems that the effects emerge when group image threat is the highest (public setting combined with the successful performance of a dissociative outgroup). We note, however, that significant differences did not emerge between the dissociative out-group and the neutral out-group (when the setting was public). A possibility is that although being outperformed by a dissociative outgroup is highly threatening, being outperformed by neutral group is still moderately threatening.

This study also provides further support for the proposed process underlying the effects. In particular, we find that comparative concerns lead to the activation of group-image motives, which in turn predict recycling intentions. Although we believe that the effects stem from awareness that the membership group has comparatively performed poorly relative to a dissociative out-group, they do not seem to arise from the desire to explicitly compete against the dissociative out-group.

Although Study 3 highlights important boundary conditions required for our effects to emerge, at least one question remains unanswered: Is simply presenting information about a dissociative out-group engaging in a behavior enough to produce the observed effects, or is a comparative element required? As highlighted by the process account in Study 3, we believe that the comparative element is an essential component for the effects to arise. We anticipate, then, that it is the comparative element per se that leads to group image concerns when the setting is public, which in turn lead to increased behavioral intentions. This is because under conditions in which people are sensitive to their public image and the comparative performance of the dissociative reference group is highlighted (i.e., a social comparison is made wherein the dissociative out-group performs better than one's membership group), the membership group's image is likely to be threatened. We therefore conducted a follow-up study - in the positively viewed domain of sustainable water consumption - to examine this additional boundary condition.

Undergraduate business students $(n=104)$ took part in small groups in a follow-up study that held the setting as public and used a one-way between-subjects design that varied the appeal type. We compared a comparative dissociative out-group with a noncomparative dissociative outgroup condition to determine whether the comparative element indeed drives the effects. For the sake of a fuller conceptual comparison, we also included a membership comparative condition. Participants were informed that the study's purpose was to shed light on people's attitudes and intentions toward water consumption. All participants were exposed to the public setting manipulation used in Study 1. Participants then viewed a press release regarding national water conservation initiatives (Appendix C), which was used to manipulate the appeal type. Again, we used province of residence to convey the actions of a dissociative out-group. In the comparative condition, the title of the press release stated, "Water Conservation in Canada: Comes Out on Top," and text revealed that "The results indicated that residents in the province of ____ are most effective in their water conservation." In the noncomparative condition, the title simply read, "Water Conservation in Canada," and the word "most" was removed from the text: "The results indicated that residents in the province of are effective in their water conservation." The membership comparative wording was similar to the wording in the dissociative comparative condition, with the exception that the name of the province of residence was used. Participants then reported their intentions toward water conservation (Appendix A; $\alpha=.803$ ). Participants also completed a seven-point measure of seriousness while carrying out the study, which we used as a covariate in the analyses.

An ANOVA on the water conservation intentions index revealed a significant main effect for appeal type $(\mathrm{F}(2,88)=$ $4.15, p<.05) .^{2}$ As we anticipated, those in the dissociative comparative condition reported greater water conservation intentions $(\mathrm{M}=5.93)$ than did those in the dissociative noncomparative condition $(\mathrm{M}=5.42 ; \mathrm{t}(88)=2.51, p<.05)$. In addition, those in the dissociative comparative condition reported greater water conservation intentions than did those in the membership comparative condition $(\mathrm{M}=5.40$; $\mathrm{t}(88)=2.61, p<.05)$.

The results of this follow-up study help further elucidate the process underlying the effects. In particular, the type of information presented about the dissociative out-group must be comparative (i.e., it must communicate that the dissociative group outperformed the participant's membership group) for the observed effects to emerge. Taken together with the mediation results of Study 3, this suggests that the activation of a comparative element is indeed necessary for the observed effects.

\section{GENERAL DISCUSSION}

Converging evidence across our studies highlights the conditions under which communicating information regarding the positive actions of a dissociative out-group can lead consumers to be more inclined to engage in that same

\footnotetext{
${ }^{2}$ We excluded participants who indicated that a province other than the home province was their place of residence $(n=6)$ or who had completed the study before $(n=1)$. The analyses were conducted on the remaining participants.
} 
behavior. In particular, we find that when the setting is public as opposed to private, consumers are more inclined to exhibit approach responses to learning of the comparative positive performance of a dissociative out-group. In the pilot study, a field study in a public context demonstrates that consumers are more likely to compost when information is presented regarding the successful performance of a dissociative out-group (vs. a membership group or no group information). In Study 1, we show that learning of the comparatively positive sustainable actions of a dissociative outgroup leads consumers to be more likely to engage in a positive sustainable consumer behavior when the setting is public as opposed to private. In Study 2, we employ an affirmation manipulation that provides evidence that the effects stem from a threat to the group level rather than individual level of the self. In Study 3, we show that the findings emerge when the behavior is positive but not negative. In addition, we show that whereas responses to a dissociative out-group differ across the public and private conditions, responses to the neutral out-group do not. Finally, Study 3 demonstrates that the activation of comparative concerns and subsequent group image motives mediated the effects.

\section{Theoretical Implications}

The current research makes a novel contribution to the existing literature by demonstrating a counterintuitive effect: that, under certain circumstances, making consumers aware of a positive action undertaken by a dissociative outgroup can make them more likely to engage in that same action. This builds on prior research that has largely demonstrated avoidance responses to attitudes and behaviors endorsed by members of dissociative out-groups (Berger and Heath 2008; Berger and Rand 2008; Dunn, White, and Dahl 2012; White and Dahl 2006, 2007). This also builds on research in normative influence in general, which has shown that although neutral or unknown others can exert descriptive normative influence (e.g., Cialdini, Reno, and Kallgren 1990; Godes and Mayzlin 2004; Naylor, Lamberton, and Norton 2011; Salganik, Dodds, and Watts 2006), people are often strongly influenced by relevant, similar, or close others. For example, consumers tend to behave similarly to those with whom they possess some degree of psychological closeness (e.g., Goldstein, Cialdini, and Griskevicius 2008), who are part of their own membership group (Terry and Hogg 1996; White, Smith, and Terry 2009), or who have other desirable qualities such as being likeable (Eagly and Chaiken 1993), attractive (Argo, Dahl, and Morales 2008), or similar to the consumer in some way (Jiang et al. 2010; Rimal and Real 2005). Thus, whereas the majority of prior research examining how reference groups can encourage similar behaviors has focused on the impact of neutral and positive reference groups, the current work highlights the conditions under which dissociative reference groups can lead consumers to act in a congruent manner.

Indeed, the current work highlights the conditions under which learning of the comparatively successful performance of a dissociative reference group will lead to approach responses on the part of consumers; we find that dissociative influence is greater when the setting is public than when it is private. Another way to view this issue is to ask whether there are times when dissociative reference groups can be more motivational in directing approach behaviors than membership groups. This is a worthwhile question given that research has typically shown that dissociative groups encourage avoidance responses (White and Dahl 2006, 2007), whereas membership groups encourage approach responses (Goldstein, Cialdini, and Griskevicius 2008; Terry and Hogg 1996; White, Smith, and Terry 2009). In our studies, we find that when the setting is public, participants show a marginal (Study 1) or significant (Study 2, Study 3, and Study 3 follow-up) tendency to exhibit more positive intentions toward the action when they receive positive performance information regarding the dissociative out-group as opposed to the membership group. Moreover, we conducted a meta-analysis across all our studies among those in the public condition (using the comparable conditions across studies; i.e., the no-affirmation condition in Study 2 and the positive behavior as the dependent measure in Study 3), comparing participants' responses in the dissociative out-group versus the membership group conditions. Using Winer's (1971; see also Labroo and Mukhopadhyay 2009) method of pooling t-values, the meta-analysis revealed that the effect was significant when considering our data as a whole $(\mathrm{z}=4.49, p<.001)$. Thus, our results also point to the conditions under which dissociative outgroups can be more likely to positively influence consumers than membership groups. Note, however, that this effect was only marginal in Study 1, so further research could profitably examine additional conditions under which consumers exhibit approach responses to dissociative outgroups compared with membership groups.

We believe that one reason why our effects emerge is because we examine conditions under which dissociative reference groups perform well on behaviors that are uniformly viewed particularly positively by others, whereas previous work has largely investigated neutral product categories (e.g., White and Dahl 2007), individual preferences (e.g., music preferences [Berger and Heath 2007], food preferences [White and Dahl 2006]), and negative behaviors (e.g., Berger and Rand 2008). Observing a dissociative group endorse a particular preference (e.g., country music) might make the individual consumer want to avoid it. However, seeing a dissociative group perform well on a behavior that is uniformly viewed as positive has the potential to increase a person's motivation to engage in that behavior as well. In one exception, Berger and Heath (2008) examined a positive behavior and found that members of a target dormitory abandoned wearing a wristband in support of a cancer charity (Livestrong) when it was adopted by a dissociative ("geeky") dormitory. We speculate that our findings differ from these previous results because we not only examine a domain that is positive but also communicate that the dissociative out-group is performing comparatively well on the behavior. The results of Study 3 and its follow-up suggest that it is indeed a process of comparative concerns activating group image motives that leads to a tendency to increase intentions and behaviors toward the positively viewed behavior. Furthermore, whereas the wristband in Berger and Heath (2008) represented a visible and material display that might indicate identity-relevant group membership, the consumer behaviors in our research are not likely to be identity relevant. In our studies, for example, composting was not situationally linked to a particular group, nor is it typically viewed as a behavior that is chronically representative of a 
particular group membership. A question remains for further research: What effects would emerge if the focal behavior were either temporarily or chronically viewed as identity relevant to the dissociative out-group (e.g., gaming skills among computer geeks)?

Whereas prior work has suggested that associative responses to a counterstereotypical person can be driven by an individual-level response (Shalev and Morwitz 2012), we demonstrate conditions under which information regarding the behaviors of a dissociative out-group as a whole can activate a group-level response that drives associative behaviors. Indeed, individual-level motives do not seem to play a role in our context given that a self-affirmation task did not attenuate the effects (Study 2) and individual image motives did not mediate our effects (Study 3 ). Thus, we propose that our effects are driven more by the salience of group-level threat (through the comparatively positive performance of a dissociative out-group in a public context) rather than individual self-threat. Notably, however, we did find in Study 3 an instance in which individual-level motives might play a role: participants in the membership condition in that study reported stronger sustainable intentions when the context was private as opposed to public. We note that although we did not anticipate this finding (and the analogous comparison did not emerge as significant in Study 1), it poses a possible direction for further research. Perhaps contexts encouraging a focus on the private self lead self-relevant membership groups to become more positively motivating. Although the focus of the current research is on the impact of dissociative reference groups on positive consumer behaviors, future studies might examine when and why a focus on the private self might lead self-relevant membership groups to have a greater influence on subsequent consumer behaviors.

\section{Managerial Implications}

The current research has important practical implications for practitioners aiming to spur consumers to engage in positive actions. Providing information regarding the comparatively positive actions of a dissociative out-group may be an effective behavior-changing strategy when a consumer's behavior is likely to be publicly viewed by others or otherwise occurs in a context that heightens public selfawareness. Our conceptualization proposes that the observed effects arise because learning of the comparatively positive actions of the dissociative out-group when public self-awareness is high threatens one's group image and subsequently heightens the desire to present one's group image in a positive light. We believe that this threat to the group image occurs because the dissociative out-group is performing well at a task that is viewed particularly positively. Indeed, Study 3 supports the notion that the effects emerge for positive behaviors but not negative behaviors. Thus, communicating information about a dissociative out-group performing comparatively well in the context of any positively viewed behavior should lead to an increase in that behavior, particularly when the consumer's actions will be seen by others. Marketers interested in encouraging other positive consumer behaviors, beyond sustainable actions, might do well to harness the positive power of dissociative out-groups. This could be relevant in a range of domains including prosocial behaviors (e.g., charitable donations, volunteering time) but could also apply to other positively viewed actions such as voting, exercising, or even solving puzzles. Further research could examine whether similar effects might be obtained in other behavioral domains.

Consistent with previous reference group research, marketers need to have an awareness of how consumers might perceive the groups used in their appeals. Most importantly, although marketers would typically want to avoid appealing to the target market in a way that invokes a dissociative outgroup in relation to the brand (White and Dahl 2006, 2007), we provide evidence that when positive consumer behaviors are encouraged, an effective means of appealing to consumers involves providing information about the positive actions of a dissociative out-group. This finding is particularly relevant given that research (White and Dahl 2006) has shown that dissociative effects can be stronger and more reliable than associative effects, suggesting that using this means to encourage consumers to engage in positive behaviors might have a more enduring effect than other appeals.

Notably, our results indicate that the effects seem to emerge in part because the positive performance information regarding a dissociative out-group is presented comparatively (Study 3 follow-up). As such, those wanting to encourage positive, prosocial actions might pit the membership group against a dissociative out-group in ways that encourage a comparative element. This might be done between groups on a university campus, between universities, between sports team fans, between two organizations, between two cities or neighborhoods, and so on. For example, many cities have a version of the "corporate challenge" whereby organizations compete against one another to raise money for charities. Our data suggest a unique lens for understanding such competitive challenges because explicit competitive motives per se may not underlie their success (Study 3); rather, it seems that emphasizing the comparative element between groups will increase the tendency to engage in the positive behavior. It seems likely then that pitting groups against one another comparatively can spur positive, prosocial actions (Study 3 follow-up). Information regarding the comparatively positive performance of a particularly dissociative organization could also be used within a focal organization to motivate employees to perform better at such challenges, in ways that ultimately benefit a common good. Notably, although we did not find evidence for the mediational role of the desire to explicitly compete with the dissociative group, this does not imply that competition never plays a role in predicting the tendency to exhibit an approach response after learning of the successful performance of a dissociative out-group. Further research could profitably examine the conditions under which explicit competition might increase positive consumer behaviors. For example, under conditions in which there are clear standards for success (e.g., rankings, benchmarks) and the comparison group is proximal to a meaningful standard (e.g., Garcia, Tor, and Gonzalez 2006), competitive concerns in response to learning of the successful performance of a dissociative out-group might play a greater role in determining consumers' reactions.

\section{Directions for Further Research}

A potential direction for further research is to examine the effects of other types of out-groups on consumer behav- 
ior. For example, scholars could explore the role of learning of the behaviors of an aspirational reference group. It may be that learning of the positive actions of an aspirational reference group could also increase inclinations to engage in positive consumer behaviors; however, it is likely that a very different mechanism would underlie such an effect. In addition, given that the comparative nature of the appeal seems to be a necessary element in our research, it would be worthwhile to examine the nature of comparisons in further detail, including how different elements of social comparison (e.g., individual factors that vary from person to person vs. situational factors in the social comparison landscape; Garcia, Tor, and Schiff 2013) might influence how consumers respond to similar appeals. For example, are people who rate high on attention to social comparison information (Beardon and Rose 1990) more susceptible to such appeals, or would the number of groups presented in the comparison affect responses (Garcia and Tor 2009)? In addition, it is possible that cultural differences in social comparison dynamics would provide a fruitful avenue for further research. For example, research has found the Japanese to be slightly more motivated than Americans by being ranked near the bottom, whereas Americans may be slightly more motivated near the top rank (Heine et al. 2001), implying that the comparative position indicated in the appeal may lead to divergent cultural responses.

Finally, in light of previous research (e.g., Berger and Rand 2008), it is noteworthy that we did not find evidence of an avoidance effect toward negative behaviors (littering) when the information appeal conveyed the actions of a dissociative out-group. A possible explanation is that littering is uniformly viewed as negative, and thus, there is a limited range in consumer responses to the behavior. Generalizing this research to other, less uniformly negative contexts thus might prove a worthwhile avenue for consumer research. For example, many vice behaviors such as drinking alcohol (Pavis, Cunningham-Burley, and Amos 1997), online gambling (Cotte and Latour 2009), and eating unhealthy foods (Freeman 2007) may be viewed as negative in general but are established as socially acceptable actions. It would be fruitful to examine conditions under which observing or learning about others engaging in these types of behaviors would lead to approach versus avoidance effects. Taken together, the current research demonstrates conditions under which learning of the comparatively successful performance of a dissociative out-group can spur consumers to engage in positive actions for the benefit of society as a whole. Given the focus of previous dissociative reference group research on avoidance behaviors and individual-level mechanisms, this research represents an important first step toward a novel theoretical development in the social influence literature.

\section{APPENDIX A: SCALE MEASURE ITEMS}

\section{Pilot Study}

Pretest Items for Reference Group (scale from 1 to 7)

-I do not want to be associated with this group.

-I want to avoid being associated with this group.

-I avoid identifying with this group.

-I strongly identify with this group. (reverse-scored)
We conducted a pretest that showed that computing science students $(\alpha=.93)$ were evaluated as being more dissociative than the scale midpoint $(M=4.80 ; \mathrm{t}(19)=3.52, p<$ $.01)$, whereas business students $(\alpha=.80)$ were less dissociative than the scale midpoint $(\mathrm{M}=2.24 ; \mathrm{t}(19)=4.76, p<$ $.001)$. In addition, computing science students were viewed as significantly more dissociative than business students $(\mathrm{t}(19)=5.80 p<.001)$.

Pretest Items for Public Nature of the Coffee Shop Setting (scale from 1-7)

-To what extent are you in a public setting right now?

-Are you in an environment where you are aware of others around you?

-To what degree can your behaviors be observed by others right now?

-To what degree are there other people that can see you right now?

-To what degree can you see other people right now?

A posttest indicated that participants $(n=30)$ in the space believed that they were in a public setting $(M=6.45$, which was significantly higher than the scale midpoint; $\mathrm{t}(29)=$ $24.08, p<.001)$.

Study 1

Intentions Toward Composting (scale from 1 to 7)

-To what degree do you intend to compost using the University of ___ composting program?

-How likely are you to take part in the University of 's composting program?

- How inclined are you to take part in the University of 's composting program?

-How willing are you to take part in University of 's composting program?

-To what degree would you be interested in learning more about the University of ___ 's composting program?

-To what degree would you be motivated to seek out additional information about the University of ___ 's composting program?

Manipulation Check for the Setting Manipulation (scale from 1 to 7 )

-To what degree are your responses going to be private? (reverse-scored)

-To what degree are your responses going to be anonymous? (reverse-scored)

-To what degree are your responses going to be made public?

-To what degree are your responses going to be discussed with others today?

Study 3

Pretest Items for Attitudes Toward Littering and Recycling (scale from 1 to 7 )

-Littering (Recycling) is a positive behavior.

-Littering (Recycling) waste is a good thing.

-I view littering (recycling) in a positive light.

Behavioral Intention Measures (scale from 1 to 7)

- How likely are you to take part in 's recycling program?

-How inclined are you to take part by recycling?

-How willing are you to take part by recycling?

-To what degree do you intend to recycle in support of the recycling program? 
-To what degree do you have positive intentions toward the recycling program?

-How likely will you be to recycle a plastic drink bottle?

-How likely will you be to recycle paper from the printer?

-How likely are you to litter?

-How inclined are you to litter?

-How willing are you to litter?

-To what degree do you intend to litter?

-To what degree do you have positive intentions toward littering?

-How likely will you be to toss an apple on the ground?

-How likely will you be to chase a small piece of paper as it blows away on the ground?

\section{Comparative Concerns}

-I feel that my province is inferior to other provinces at this moment.

-I am unhappy with how my province compares to other provinces.

-I feel frustrated or rattled about my province's performance.

-I am displeased by my province's current performance.

\section{Group Image Concerns}

-I am concerned with the publicly displayed aspects of the province I live in.

-I am self-conscious about the way my province looks to others.

-I am concerned about the way my province looks to others.

-I wish to avoid having my province look foolish.

-I want to present a positive view of my province to others.

-I want my province to be viewed positively by others.

-I want my province to look good to others.

Individual Self-Image Concerns

-I am concerned with the publicly displayed aspects of myself.

-I am self-conscious about the way I look to others.

-I am concerned about the way I present myself to others.

-I wish to avoid looking foolish.

-I want to present a positive view of myself to others.

-I want to be viewed positively by others.

-I want to look good to others.

\section{Explicit Competition}

-I want my province to compete against other provinces.

-I want to show that my province can win.

-I feel a sense of competition between my province and other provinces.

-I want to show that my province is the best.

-I want to demonstrate that my province can come out on top.

-I want to show that my province can outperform other provinces.

Accountability

-I feel accountable for my province's performance.

-I feel responsible for my province's outcomes.

-I feel like I should do more to help my province recycle (prevent litter).

\section{Study 3 Follow-Up}

\section{Water Conservation Intentions}

-How likely are you to conserve water?

-How inclined are you to conserve water?

-How willing are you to conserve water?

-To what degree do you intend to conserve water?

-How likely will you be to turn off the tap when you brush your teeth?

-How likely will you be to shorten the length of your showers?

\section{APPENDIX B: PRESS RELEASE (STUDY 1)}

Composting on the University of Campus: Business (Computing Science) Students Come Out on Top

The Office of Sustainability at the University of is excited to announce that new waste management infrastructure will be in place on campus in 2012. The decision to implement new composting infrastructure follows a comprehensive study completed by the Office of Sustainability, which examined waste diversion behaviors on campus. The study results revealed that the University of

doing well in diverting waste from landfills but much improvement is needed, particularly in diverting compostable organics.

The study also examined the particular behaviors of faculties and departments across campus. The results indicated that business (computing science) students are the most effective in composting efforts when comparing across the student groups. Our goal is to get you to compost too.

Composting is a natural disposal of organics by collecting the waste and allowing it to decompose naturally and quickly, becoming useful as fertilizer and returning valuable nutrients to the soil. About one-third of garbage generated is compostable. At the University of , food, leaf and lawn waste are composted on campus and the compost is returned to grounds. However, if these efforts are to really make an impact, members of the campus community need to be strongly encouraged to compost.

For more information contact:

Office of Sustainability

University of

Address

\section{APPENDIX C: PRESS RELEASE (STUDY 3)}

\section{Positive Behavior}

Recycling in Canada: Residents Come Out on Top

Environment Canada is excited to announce that enhanced recycling programs will be rolling out across the country in 2013. The decision to implement further recycling programs follows a comprehensive study completed by the Government of Canada, which examined recycling across the country.

The study also examined the particular behaviours of provinces across Canada. The results indicated that residents in the province of are most effective in their recycling when comparing across provinces, with $90 \%$ of people in recycling effort. taking part in some form of measurable

Recycling is the processing of used materials, such as glass, paper, metal, plastic, textiles, and electronics, into new products to prevent waste of potentially useful materials. As part of the enhanced recycling program across Canada, the upcoming campaign will encourage increased recycling efforts through programs such as curbside recycling pick-up and community recycling depots. Recycling is also being promoted through new financial incentives for certain recyclable materials.

For more information contact: Environment Canada 4999-98 Avenue, Room 200 Edmonton, Alberta T6B 2X3 780-951-8600 enviroinfo@ec.gc.ca 


\section{Negative Behavior}

Littering in Canada: Residents Come Out on Top

Environment Canada is excited to announce that enhanced littering prevention programs will be rolling out across the country in 2013. The decision to implement further littering prevention programs follows a comprehensive study completed by the Government of Canada, which examined littering across the country.

The study also examined the particular behaviours of provinces across Canada. The results indicated that residents in the province of ________ litter most often when comparing across provinces, with $90 \%$ of people in taking part in some form of littering.

Litter consists of waste products that have been disposed of improperly, without consent, in an inappropriate location. As part of the enhanced litter prevention programming across Canada, the upcoming campaign will increase signage to encourage minimizing litter through actions such as proper waste disposal. Littering is also being discouraged through increased fine penalties for littering behaviour.

For more information contact: Environment Canada, 4999-98 Avenue, Room 200, Edmonton, Alberta T6B 2X3; 780-951-8600, enviroinfo@ec.gc.ca

\section{REFERENCES}

Argo, Jennifer J., Darren W. Dahl, and Andrea C. Morales (2008), "Positive Consumer Contagion: Responses to Attractive Others in a Retail Context," Journal of Marketing Research, 45 (December), 690-701.

Baumeister, Roy F., E.J. Masicampo, and C. Nathan DeWall (2009), "Prosocial Benefits of Feeling Free: Disbelief in Free Will Increases Aggression and Reduces Helpfulness," Personality and Social Psychology Bulletin, 35 (2), 260-68.

Beardon, William O. and Randall L. Rose (1990), “Attention to Social Comparison Information: An Individual Difference Factor Affecting Consumer Conformity," Journal of Consumer Research, 16 (4), 461-71.

Berger, Jonah (2008), "Identity Signaling, Social Influence, and Social Contagion," in Understanding Peer Influence in Children and Adolescents, Mitch Prinstein and Ken Dodge, eds. New York: Guilford Press, 181-99.

_ and Chip Heath (2007), "Where Consumers Diverge from Others: Identity Signaling and Product Domains," Journal of Consumer Research, 34 (2), 121-34.

— and — (2008), "Who Drives Divergence? Identity Signaling, Out-Group Similarity, and the Abandonment of Cultural Tastes," Journal of Personality and Social Psychology, 95 (3), 593-607.

_ and Devin Pope (2011), "Can Losing Lead to Winning?" Management Science, 57 (5), 817-27.

_ and Lindsay Rand (2008), "Shifting Signals to Help Health: Using Identity Signaling to Reduce Risky Health Behaviors," Journal of Consumer Research, 35 (2), 509-518.

Brewer, Marilynn (1991), "The Social Self: On Being the Same and Different at the Same Time," Personality and Social Psychology Bulletin, 17 (5), 475-82.

Cialdini, Robert B., Raymond R. Reno, and Carl A. Kallgren (1990), "A Focus Theory of Normative Conduct: Recycling the Concept of Norms to Reduce Littering in Public Places," Journal of Personality and Social Psychology, 58 (6), 1015-26.

Cotte, June and Kathryn A. Latour (2009), "Blackjack in the Kitchen: Understanding Online Versus Casino Gambling," Journal of Consumer Research, 35 (5), 742-58.
Derks, Belle, Colette van Laar, and Naomi Ellemers (2009), "Working for the Self or Working for the Group: How Self- Versus Group Affirmation Affects Collective Behavior in Low-Status Groups," Journal of Personality and Social Psychology, 96 (1), 183-202.

Dunn, Lea, Katherine White, and Darren W. Dahl (2012), "That Is So Not Me: Dissociating from Undesired Consumer Identities," in The Routledge Companion to Identity and Consumption, Ayalla A. Ruvio and Russell W. Belk, eds. New York: Routledge.

Eagly, Alice H. and Shelly Chaiken (1993), The Psychology of Attitudes. Orlando, FL: Harcourt Brace Jovanovich.

Englis, Basil G. and Michael R. Solomon (1995), "To Be and Not to Be: Lifestyle Imagery, Reference Groups, and 'The Clustering of America," Journal of Advertising, 24 (1), 13-28.

Environmental Protection Agency (2011), "Municipal Solid Waste in the United States: 2010 Facts and Figures Sheet," (accessed April 24, 2014), [available at http://www.epa.gov/osw/nonhaz/ municipal/msw99.htm].

Ferraro, Rosellina, James R. Bettman, and Tanya L. Chartrand (2009), "The Power of Strangers: The Effect of Incidental Consumer Brand Encounters on Brand Choice," Journal of Consumer Research, 35 (5), 729-41.

Festinger, Leon (1957), A Theory of Cognitive Dissonance. Evanston, IL: Row, Peterson.

Freeman, Andrea (2007), "Fast Food: Oppression Through Poor Nutrition," California Law Review, 95 (6), 2221-59.

Froming, William J., G. Rex Walker, and Kevin J. Lopyan (1982), "Public and Private Self-Awareness: When Personal Attitudes Conflict with Societal Expectations," Journal of Experimental Social Psychology, 18 (5), 476-87.

Garcia, Stephen, M. and Avishalom Tor (2009), "The N-Effect: More Competitors, Less Competition," Psychological Science, 20 (7), 871-77.

—_, , and Richard Gonzalez (2006), "Ranks and Rivals: A Theory of Competition," Personality and Social Psychology Bulletin, 32 (7), 970-82.

—, , and Tyrone M. Schiff (2013), "The Psychology of Competition: A Social Comparison Perspective," Perspectives on Psychological Science, 8 (6), 634-50.

Godes, David and Dina Mayzlin (2004), "Using Online Conversations to Study Word-of-Mouth Communication," Marketing Science, 23 (4), 545-60.

Goldstein, Noah J., Robert B. Cialdini, and Vladas Griskevicius (2008), "A Room with a Viewpoint: Using Social Norms to Motivate Environmental Conservation in Hotels," Journal of Consumer Research, 35 (3), 472-82.

Hass, R. Glen (1984), "Perspective Taking and Self-Awareness: Drawing an E on Your Forehead," Journal of Personality and Social Psychology, 46 (4), 788-98.

Hayes, Andrew F. (2013), "PROCESS," (accessed April 24, 2014), [available at http://www.afhayes.com/introduction-to-mediationmoderation-and-conditional-process-analysis.html].

Heine, Steven J., Shinobu Kitayama, Darrin R. Lehman, Toshitaki Takata, Eugene Ide, Cecilia Leung, and Hisaya Matsumoto (2001), "Divergent Consequences of Success and Failure in Japan and North America: An Investigation of Self-Improving Motivations and Malleable Selves," Journal of Personality and Social Psychology, 81 (4), 599-615.

Hoshino-Browne, Etsuko, Adam S. Zanna, Steven J. Spencer, Mark P. Zanna, Shinobu Kitayama, and Sandra Lackenbauer (2001), "On the Cultural Guises of Cognitive Dissonance: The Case of Easterners and Westerners," Journal of Personality and Social Psychology, 89 (3), 294-310.

Howell, D.C. (1997). Statistical Methods for Psychology, 4th ed. Belmont, CA: Wadsworth Publishing Company. 
Jiang, Lan, JoAndrea Hoegg, Darren W. Dahl, and Amitava Chattopadhyay (2010), "The Persuasive Role of Incidental Similarity on Attitudes and Purchase Intentions in a Sales Context," Journal of Consumer Research, 36 (5), 778-91.

Labroo, Aparna A. and Anirban Mukhopadhyay (2009), "Lay Theories of Emotion Transience and the Search for Happiness: A Fresh Perspective on Affect Regulation," Journal of Consumer Research, 36 (2), 242-54.

Lerner, Jennifer S. and Philip E. Tetlock (1999), “Accounting for the Effects of Accountability," Psychological Bulletin, 125 (2), 255-75.

McFarland, Cathy and Dale T. Miller (1994), "The Framing of Relative Performance Feedback: Seeing the Glass as Half Empty or Half Full," Journal of Personality and Social Psychology, 66 (6), 1061-73.

Naylor, Rebecca W., Cait P. Lamberton, and David A. Norton (2011), "Seeing Ourselves in Others: Reviewer Ambiguity, Egocentric Anchoring, and Persuasion," Journal of Marketing Research, 48 (June), 617-31.

Organisation for Economic Co-operation and Development (2008), Promoting Sustainable Consumption. Paris: OECD Publications.

Pavis, Stephen, Sarah Cunningham-Burley, and Amanda Amos (1997), "Alcohol Consumption and Young People: Exploring Meaning and Social Context," Health Education Research, 12 (3), 311-22.

Peattie, Ken (2010), "Green Consumption: Behavior and Norms," Annual Review of Environment and Resources, 35, 195-28.

Ratner, Rebecca and Barbara Kahn (2002), "The Impact of Private Versus Public Consumption on Variety-Seeking Behavior," Journal of Consumer Research, 29 (2), 246-57.

Rimal, Rajiv N. and Kevin Real (2005), "How Behaviors Are Influenced by Perceived Norms: A Test of the Theory of Normative Social Behavior," Communication Research, 32 (3), 389414.

Salganik, Matthew J., Peter S. Dodds, and Duncan J. Watts (2006), "Experimental Study of Inequality and Unpredictability in an Artificial Cultural Market," Science, 311 (5762), 854-56.

Shalev, Edith and Vicki G. Morwitz (2012), "Influence via Comparison-Driven Self-Evaluation and Restoration: The Case of the Low-Status Influencer," Journal of Consumer Research, 38 (5), 964-80.

Sherman, David K., Zoe Kinias, Brenda Major, Heejung S. Kim, and Mary Prenovost (2007), "The Group as a Resource: Reducing Biased Attributions for Group Success and Failure via Group Affirmation," Personality and Social Psychology Bulletin, 33 (8), 1100-1112.

Steele, Claude M. (1988), "The Psychology of Self-Affirmation: Sustaining the Integrity of the Self," in Advances in Experimental Social Psychology, Vol. 21, Leonard Berkowitz, ed. New York: Academic Press, 261-302. and Thomas J. Liu (1983), "Dissonance Processes as SelfAffirmation," Journal of Personality and Social Psychology, 45 (1), 5-19.

Tajfel, Henri and John C. Turner (1986), The Social Identity Theory of Intergroup Behavior. Chicago: Nelson-Hall.

Tauer, John M. and Judith M. Harackiewicz (1999), "Winning Isn't Everything: Competition, Achievement Orientation, and Intrinsic Motivation," Journal of Experimental Social Psychology, 35 (3), 209-238.

Terry, Deborah J. and Michael A. Hogg (1996), "Group Norms and the Attitude-Behavior Relationship: A Role for Group Identification," Personality and Social Psychology Bulletin, 22 (8), 775-93.

Turner, Rhiannon N. and Richard J. Crisp (2007), Essential Social Psychology. London: Sage Publications.

WaterAid America (2013), "Statistics," (accessed April 24, 2014), [available at http://www.wateraidamerica.org/what_we_do/ statistics.aspx].

White, Katherine and Jennifer J. Argo (2009), "Social Identity Threat and Consumer Preferences," Journal of Consumer Psychology, 19 (3), 313-25.

$-\ldots, \ldots$, and Jaideep Sengupta (2012), "Dissociative Versus Associative Responses to Social Identity Threat: The Role of Consumer Self-Construal," Journal of Consumer Research, 39 (4), 704-719.

— and Darren W. Dahl (2006), "To Be or Not Be: The Influence of Dissociative Reference Groups on Consumer Preferences," Journal of Consumer Psychology, 16 (4), 404-413.

— and - (2007), "Are All Outgroups Created Equal? Consumer Identity and Dissociative Influence," Journal of Consumer Research, 34 (4), 525-36.

and John Peloza (2009), "Self-Benefit Versus Other-Benefit Marketing Appeals: Their Effectiveness in Generating Charitable Support," Journal of Marketing, 73 (July), 109-124.

— a and Bonnie Simpson (2013), "When Do (and Don't) Normative Appeals Influence Sustainable Consumer Behaviors?" Journal of Marketing, 77 (March), 78-95.

_ , Joanne R. Smith, and Deborah J. Terry, (2009), "Social Influence in the Theory of Planned Behavior: The Role of Descriptive, Injunctive and In-Group Norms," British Journal of Social Psychology, 48 (1), 135-58.

Winer, Benjamin J. (1971), Statistical Principles in Experimental Design. New York: McGraw-Hill.

Zhao, Xinshu, John G. Lynch Jr., and Qimei Chen (2010), "Reconsidering Baron and Kenny: Myths and Truths About Mediation Analysis," Journal of Consumer Research, 37 (2), 197-206. 
Copyright of Journal of Marketing Research (JMR) is the property of American Marketing Association and its content may not be copied or emailed to multiple sites or posted to a listserv without the copyright holder's express written permission. However, users may print, download, or email articles for individual use. 